Erratum

\title{
Development of insect resistance in tomato plants expressing the $\delta$-endotoxin gene of Bacillus thuringiensis subsp. tenebrionis
}

Seong-Lyul Rhim ${ }^{1, *}$ Hwa-Jin Cho ${ }^{2}$, Byung-Dong Kim ${ }^{2}$, Wolfgang Schnetter ${ }^{3}$ and Klaus Geider ${ }^{4}$

${ }^{1}$ Department of Genetic Engineering and Institute of Environment and Life Sciences, Hallym University, Chuncheon, 200-702, Korea ( ${ }^{*}$ author for correspondence); ${ }^{2}$ Department of Horticulture, College of Agriculture and Life Sciences, Seoul National University, Suwon 441-744, Korea; ${ }^{3}$ Department of Zoology, University of Heidelberg, Germany; ${ }^{4}$ Max-Planck-Institute of medical Research, Heidelberg, Germany

Molecular Breeding 1: 229-236, 1995.

By mistake the indication of the corresponding author has been omitted. The corresponding author is S.-L. Rhim. 